\title{
Glucocorticoid management of adrenal insufficiency in the United Kingdom: assessment using real-world data
}

\author{
Kamran Iqbal', Kate Halsby ${ }^{2}$, Robert D Murray ${ }^{3}$, Paul V Carroll ${ }^{4}$ and Robert Petermann ${ }^{5}$ \\ 'Shire, London, UK \\ ${ }^{2} \mathrm{pH}$ Associates, Marlow, UK \\ ${ }^{3}$ Leeds Centre for Diabetes \& Endocrinology, St James's University Hospital, Leeds, UK \\ ${ }^{4}$ Department of Endocrinology, Guy's \& St. Thomas' NHS Foundation Trust, London, UK \\ ${ }^{5}$ Shire, Vienna, Austria
}

Correspondence should be addressed to K Halsby: kate.halsby@gmail.com

\begin{abstract}
Background and objectives: Glucocorticoids are used to manage adrenal insufficiency (Al). We describe treatments used in the United Kingdom and real-world clinical outcomes for each treatment.

Methods: We used 2010-2016 primary care data from The Health Improvement Network (THIN). Descriptive analyses were conducted, and differences in variables between patients prescribed immediate-release hydrocortisone (IR HC), prednisolone or modified-release hydrocortisone (MR HC) were assessed using Fisher's exact test. Results: Overall, 2648 patients were included: 1912 on IR HC (72\%), 691 on prednisolone (26\%) and 45 (2\%) on MR HC. A total of $1174(44.3 \%)$ had primary and $1150(43.4 \%)$ had secondary Al. Patients on prednisolone were older $(P<0.001)$ and had a greater history of smoking $(292 / 691, P<0.001)$ and CVD $(275 / 691, P<0.001)$. Patients on MR HC had more PCOS $(3 / 45, P=0.001)$ and diabetes $(27 / 45, P=0.004)$. The number of GP visits/ patient/year was 6.50 in IR HC, 9.54 in prednisolone and 9.11 in MR HC cohorts. The mean number of A\&E visits and inpatient and outpatient hospital admissions ranged from 0.42 to 0.93 visits/patient/year. The mean number of adrenal crises/patient/year was between 0.02 and 0.03 for all cohorts.

Conclusion: IR HC is most commonly used for the management of $\mathrm{Al}$ in the United Kingdom, followed by prednisolone. Few patients receive MR HC. The prednisolone and MR HC cohorts displayed a greater prevalence of vascular risk factors compared with IR HC. The occurrence of AC and primary and secondary resource use were similar between treatment cohorts, and they indicate significant resource utilisation. Improved treatment and management of patients with $\mathrm{Al}$ is needed.
\end{abstract}

\section{Key Words \\ - adrenal insufficiency \\ - hydrocortisone \\ - modified-release \\ - outcome \\ resource}

\section{Introduction}

Adrenal insufficiency (AI) is a chronic, rare, potentially fatal condition. Primary AI (also known as Addison's disease or hypoadrenalism) is caused by the loss of function of the adrenal cortex, whereas secondary AI results from a dysfunction of the integrity of the hypothalamic-pituitary-adrenal axis. Primary AI is less common than secondary AI, with an estimated prevalence of $93-140$ per million compared to 150-280 per million, respectively (1). Addison's disease is more common in women and in those aged
This work is licensed under a Creative Commons Attribution 4.0 International License. 
between 30 and 50 years old (2), although it can present at any age.

Patients with AI need to take daily life-long medication. This consists of a glucocorticoid, typically hydrocortisone (HC) or prednisolone, and in primary AI, a mineralocorticoid analogue (fludrocortisone), with the aim to replace the missing cortisol and aldosterone, respectively. Conventional immediate-release (IR) HC does not replicate the physiological circadian rhythm of endogenous cortisol secretion. Patients experience impaired quality of life (QoL) and there is increased mortality (3). Patients on IR HC must take either twice or thrice daily doses. Inadequate glucocorticoid replacement or insufficient increases during stress may result in adrenal crisis (AC), which typically requires inpatient hospitalisation. AC can occur very quickly and be very severe, leading to coma or death if untreated (4). Modified-release (MR) HC was licensed in 2011 to treat adults with AI (5). It is given once daily and more closely mimics the daytime circadian rhythm of cortisol secretion (6). The safety and efficacy of MR HC has been demonstrated in clinical trials (7). Bergthorsdottir et al. report a better health-related QoL in patients with AI who received the MR formulation compared with IR HC (8). Recently, Isidori et al. reported that AI patients switching from conventional IR HC therapy to MR HC lost significantly more body weight, developed a more normal cellular immune profile and had an improved QoL (9). Prednisolone is taken once daily and has the benefit of clinical familiarity. There is an absence of evidence for inferiority when compared to HC (10). The cost for 28-day treatment is $£ 1$ for prednisolone $5 \mathrm{mg}$ daily, $£ 81$ for IR HC $20 \mathrm{mg}$ daily and $£ 224$ for MR HC $20 \mathrm{mg}$ daily (11).

There is a paucity of data regarding the choice of treatments for AI in real-world clinical practice in the United Kingdom (UK). Also, data regarding the clinical outcomes and resource use in patients with AI treated with different formulations of $\mathrm{HC}$ and prednisolone are lacking. These data may aid decision making for payers, commissioners and healthcare professionals. This study aimed to describe the real-world management and clinical outcomes of patients with AI within the UK. To achieve this, we used The Health Improvement Network (THIN) to describe primary and secondary health care resource use, treatment outcomes (including frequency of AC) and health-economic analyses.

\section{Subjects and methods}

\section{Study design and data sources}

A retrospective, observational study was conducted in routine primary care. All variables were identified from THIN database. As of 2016, THIN comprised the pseudonymised electronic primary care records of more than 15 million patients from over 700 general practices (GPs) in the UK (personal communication, IMS World Publications Real-World Evidence Solutions, May 2017). THIN contains information on patient demographics, diagnoses and procedures, referrals, laboratory tests and GP prescriptions, as well as details of hospitalisations and hospital visits via letters from or to secondary care. Diagnoses are recorded using Read codes, and prescriptions are entered using Multilex codes, which can easily be linked to British National Formulary codes (12). THIN is demographically representative of the UK population (13). Numerous studies have utilised THIN for research, and it has been shown that both the clinical diagnostic and prescribing information is well recorded and accurate $(13,14)$.

\section{Study population}

The population of interest comprised patients with treated AI defined as an AI-specific Read code and at least one Multilex code for the corticosteroids of interest (i.e. IR HC, prednisolone or MR HC) between 2010 and 2016. To ensure the whole population of interest was captured, all AI-specific Read codes were selected, and division of Read codes into primary or secondary AI was agreed by clinical experts in the field (Supplementary Table 1, see section on supplementary data given at the end of this article). Patients were grouped into the following three treatment cohorts based on their first prescription within the time period of interest (or their first MR HC prescription for Cohort 3) assuming that the first prescription was representative of the patient's treatment history:

- Cohort 1 (IR HC): All patients with a Read code for AI and a prescription of IR HC but no prescription for MR HC, between 2010 and 2016, and no earlier prescription for IR prednisolone during this period.

- Cohort 2 (IR prednisolone): All patients with a Read code for AI and a prescription of IR prednisolone between 2010 and 2016 but no prescription for MR
This work is licensed under a Creative Commons Attribution 4.0 International License. ded from Bioscientifica.com at $04 / 26 / 2023$ 12:27:24PM 
$\mathrm{HC}$ at any time during this period, and no earlier prescription for IR HC during this period.

- Cohort 3 (MR HC): All patients with a Read code for AI and a prescription of MR HC between 2010 and 2016.

\section{Data extraction and management}

Data on demographics (age and sex), Townsend score (measure of deprivation), primary and secondary care resource use, prescribed medications, occurrence of AC, first AI Read code recorded and vascular risk factors were extracted for all patients in cohorts $1-3$. Data regarding primary care resource use included number of face-to-face GP and nurse visits, home visits and phone call contacts. Data extracted regarding secondary care resource use included number of accident and emergency (A\&E) visits and inpatient and outpatient hospital admissions (including referrals per patient by specialty). Information on prescribed medications included the duration of time on medication and dosage, where available. Data extracted regarding risk factors included weight; BMI; blood pressure (all at first prescription of corticosteroid within study period); and a history of diabetes, smoking, high alcohol consumption, cardiovascular disease (CVD), non-alcoholic fatty liver disease (NAFLD), polycystic ovary syndrome (PCOS) and stress. Full code lists are available from the study authors. Where possible, patients were grouped by diagnosis into either primary or secondary AI by clinical experts based on their Read codes (Supplementary Table 1).

Data were managed in accordance with standard THIN guidelines, including the use of appropriate quality checks. Records of the same resource type (i.e. inpatient, $A \& E$, outpatient) found within 6 weeks (42 days) were counted as the same secondary care episode. A full list of the assumptions applied to the data is available from the study authors.

\section{Data analysis}

Descriptive analyses were conducted using Stata (v14 Statacorps, College Station, TX, USA). Distributions and descriptive statistics of both central tendency (medians and arithmetic or geometric means) and dispersion (standard deviation (s.D.) and interquartile range (IQR)) were produced for quantitative variables. Categorical variables were described with frequencies and percentages. Differences between the treatment cohorts for all variables were assessed using Fisher's exact test (with the continuous data grouped into categories). $P$ values from the tests are used to indicate trends rather than for hypothesis testing. Subgroup analyses were also carried out to assess the differences in variables between treatment cohorts by subgroup of AI (i.e. primary or secondary).

The number of AC per patient was used to calculate the mean number of AC per patient per year after the first prescription, adjusting for patients' time in the study. Each patient's time in the study was calculated from their first prescription date for one of the drugs of interest within the study time period (January 2010 to December 2016), to the patient leaving the study (whether through death, by transferring out of their GP practice or at their last date of data collection prior to the end of the study in December 2016).

The summary statistics for patients' primary and secondary resource use were used to estimate the annual cost of an AI patient to the National Health Service (NHS). Reference costs for each variable were obtained from the Personal Social Services Research Unit (15) and the National Schedule (16). The reference costs were applied to the primary and secondary resource use per patient per year and added to the drug costs, to obtain an approximate cost per year per patient by treatment cohort.

\section{Ethics}

This study was approved by THIN's Scientific Review Committee (Reference: 16THIN080/16THIN054). NHS Research Ethics Committee approval was not sought since THIN is a publicly available data source, and patient consent was not sought since organisation-level consent is provided by the individual GP practices which contribute data to THIN, and only anonymised data were accessed. The study details were registered on Clinicaltrials.gov (reference NCT03013166).

\section{Results}

From the total THIN1601 dataset of 15,039,292 patients, a total of 3601 patients had a diagnosis of AI and a prescription for oral corticosteroids; these records were extracted for analysis. Refer to Figure 1 for flowchart of study population. A total of 2648 patients with a prescription for corticosteroid(s) after 1st January 2010 were included in the analyses: 1912 (72.2\%) in the IR HC cohort, 691 (26.1\%) in the prednisolone cohort and $45(1.7 \%)$ in the MR HC cohort (Fig. 2). The 2648 study patients were also divided into primary and secondary AI 


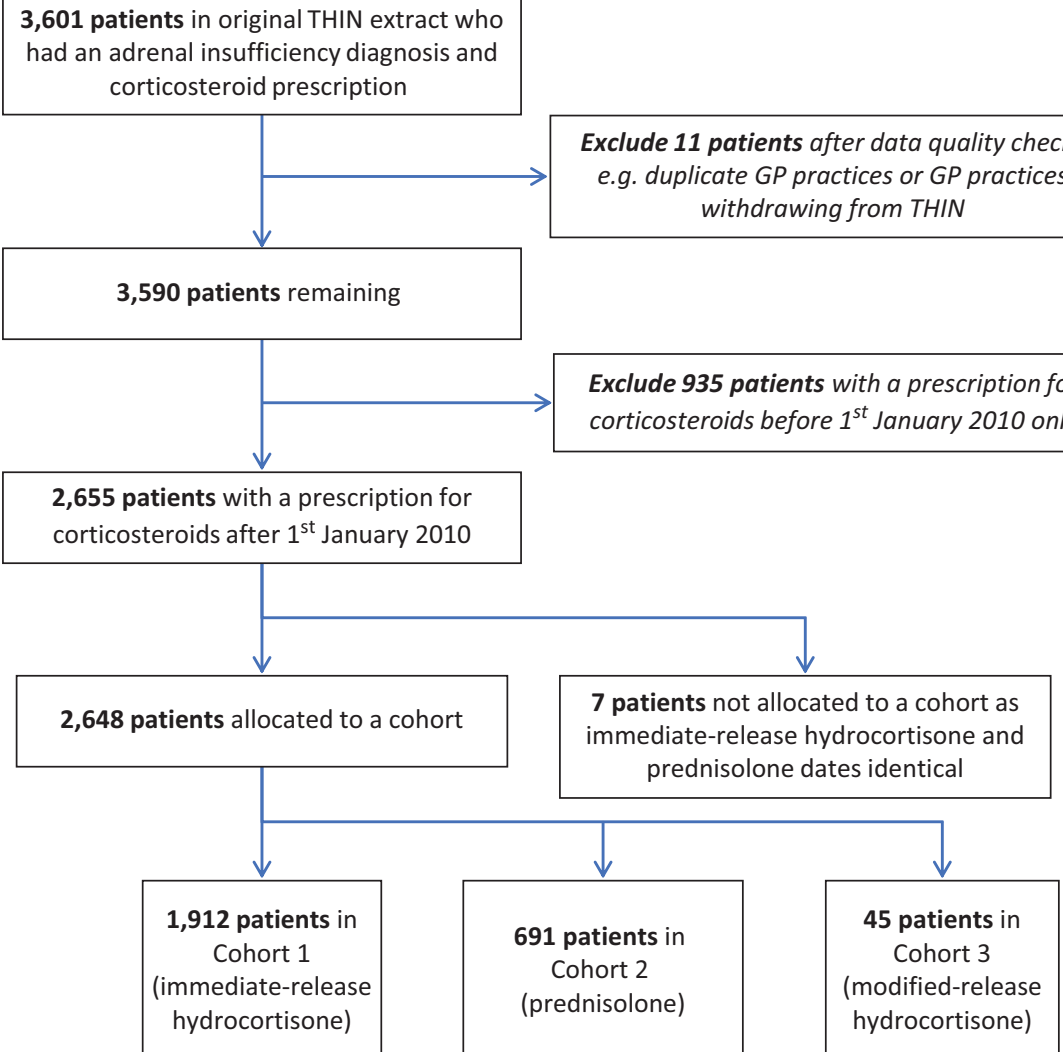

Figure 1

Flowchart of study population. based on their Read codes. A total of 1174 (44.3\%) had primary AI, with the most common diagnosis recorded as Addison's disease (71.9\%), whilst 1150 (43.4\%) had secondary AI, with most common diagnosis recorded as pituitary adenoma (59.5\%). For 324 patients (12.2\%), the classification into primary vs secondary AI could not be determined based only on the Read codes (Supplementary Table 1). Of the 1174 patients with primary AI, 863 (73.5\%) were in the IR HC cohort, 293 (25.0\%) in the prednisolone cohort and 18 (1.5\%) in the MR HC cohort (Fig. 2). Of the 1150 patients with secondary AI, 857 (74.5\%) were in the
IR HC cohort, $272(23.6 \%)$ in the prednisolone cohort and $21(1.8 \%)$ in the MR HC cohort (Fig. 2).

\section{Demographics and risk factors}

Over $40 \%$ of patients in each cohort were aged over 60 years. Patients in the prednisolone cohort were slightly older than patients in the other treatment cohorts (Table $1 ; P<0.001$ ). The mean age was 51.7 years in the IR HC cohort, 56.3 years in the prednisolone cohort and 55.7 years in the MR HC cohort. Fifty per cent of patients

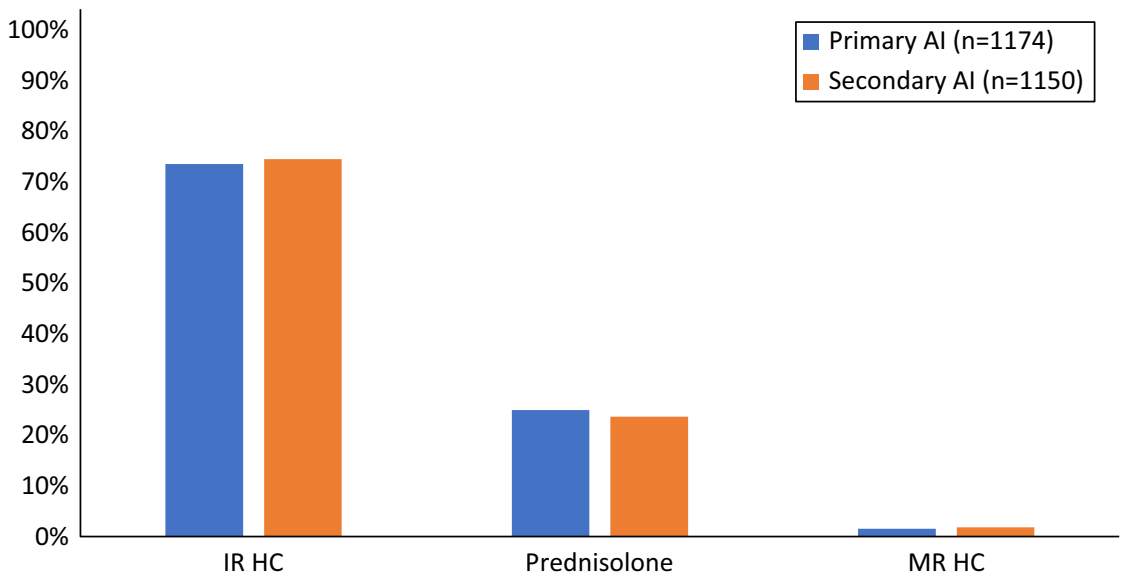

\section{Figure 2}

Breakdown of treatment choice for patients with primary and secondary adrenal insufficiency in the UK. Al, adrenal insufficiency; $\mathrm{HC}$, hydrocortisone; IR, immediate-release; MR, modified-release. https://ec.bioscientifica.com

https://doi.org/10.1530/EC-18-0418 (c) 2019 The authors Published by Bioscientifica Ltd
This work is licensed under a Creative Commons Attribution 4.0 International License. 
Table 1 Demographics and risk factors of patients with adrenal insufficiency, by cohort.

\begin{tabular}{|c|c|c|c|c|c|c|c|}
\hline & $\begin{array}{l}\text { Cohort 1: } \\
\text { release hy }\end{array}$ & $\begin{array}{l}\text { diate- } \\
\text { tisone }\end{array}$ & Cohort 2: & solone & $\begin{array}{r}\text { Cohort } 3 \\
\text { release hy }\end{array}$ & $\begin{array}{l}\text { ified- } \\
\text { rtisone }\end{array}$ & \\
\hline & $n$ & $\%$ & $n$ & $\%$ & $n$ & $\%$ & $P$ value \\
\hline Sex & & & & & & & \\
\hline$n$ & 1912 & & 691 & & 45 & & $<0.001$ \\
\hline Male & 961 & 50.3 & 275 & 39.8 & 19 & 42.2 & \\
\hline Female & 951 & 49.7 & 416 & 60.2 & 26 & 57.8 & \\
\hline Age (years) & & & & & & & \\
\hline$n$ & 1912 & & 691 & & 45 & & $<0.001$ \\
\hline Mean & 51.7 & & 56.3 & & 55.7 & & \\
\hline $0-20$ & 184 & 9.6 & 43 & 6.2 & 2 & 4.4 & \\
\hline $20-40$ & 349 & 18.3 & 96 & 13.9 & 11 & 24.4 & \\
\hline $40-60$ & 612 & 32 & 219 & 31.7 & 11 & 24.4 & \\
\hline $60+$ & 767 & 40.1 & 333 & 48.2 & 21 & 46.7 & \\
\hline Weight (kg) & & & & & & & \\
\hline$n$ & 1258 & & 519 & & 20 & & 0.218 \\
\hline Mean & 78.2 & & 78.1 & & 82.7 & & \\
\hline$<50$ & 85 & 6.8 & 33 & 6.4 & 0 & 0 & \\
\hline $50-75$ & 455 & 36.2 & 215 & 41.4 & 6 & 30 & \\
\hline $75-100$ & 534 & 42.4 & 193 & 37.2 & 12 & 60 & \\
\hline $100+$ & 184 & 14.6 & 78 & 15 & 2 & 10 & \\
\hline Body mass index* & & & & & & & \\
\hline$n$ & 1159 & & 503 & & 18 & & 0.078 \\
\hline Mean & 28.5 & & 28.7 & & 29.5 & & \\
\hline Underweight/normal & 338 & 29.2 & 167 & 33.2 & 5 & 27.8 & \\
\hline Overweight & 423 & 36.5 & 153 & 30.4 & 4 & 22.2 & \\
\hline Obese class I & 247 & 21.3 & 101 & 20.1 & 6 & 33.3 & \\
\hline Obese class II & 151 & 13 & 82 & 16.3 & 3 & 16.7 & \\
\hline Blood pressure** & & & & & & & \\
\hline$n$ & 1561 & & 617 & & 30 & & 0.442 \\
\hline Normal & 962 & 61.6 & 382 & 61.9 & 22 & 73.3 & \\
\hline Low & 69 & 4.4 & 23 & 3.7 & 0 & 0 & \\
\hline High & 526 & 33.7 & 207 & 33.6 & 8 & 26.7 & \\
\hline Low/high & 4 & 0.3 & 5 & 0.8 & 0 & 0 & \\
\hline Diabetes & & & & & & & \\
\hline$n$ & 1912 & & 691 & & 45 & & 0.004 \\
\hline Yes & 1006 & 52.6 & 316 & 45.7 & 27 & 60 & \\
\hline Smoker & & & & & & & \\
\hline$n$ & 1912 & & 691 & & 45 & & $<0.001$ \\
\hline Yes & 535 & 28 & 292 & 42.3 & 16 & 35.6 & \\
\hline High alcohol & & & & & & & \\
\hline$n$ & 1912 & & 691 & & 45 & & 0.068 \\
\hline Yes & 114 & 6 & 57 & 8.2 & 1 & 2.2 & \\
\hline CVD & & & & & & & \\
\hline$n$ & 1912 & & 691 & & 45 & & $<0.001$ \\
\hline Yes & 539 & 28.2 & 275 & 39.8 & 15 & 33.3 & \\
\hline NAFLD & & & & & & & \\
\hline$n$ & 1912 & & 691 & & 45 & & 0.501 \\
\hline Yes & 15 & 0.8 & 9 & 1.3 & 0 & 0 & \\
\hline PCOS & & & & & & & \\
\hline$n$ & 1912 & & 691 & & 45 & & 0.001 \\
\hline Yes & 21 & 1.1 & 18 & 2.6 & 3 & 6.7 & \\
\hline Stress & & & & & & & \\
\hline$n$ & 1912 & & 691 & & 45 & & 0.060 \\
\hline Yes & 330 & 17.3 & 147 & 21.3 & 7 & 15.6 & \\
\hline Townsend score ${ }^{\#}$ (S.D.) & $2.71(1.35)$ & & $2.84(1.37)$ & & $2.36(1.45)$ & & \\
\hline
\end{tabular}

*Underweight: <18.5; normal: 18.5-24.99; overweight: 25-29.99; obese class I: 30-34.99; obese class II: $\geq 35$; **normal range: $90-140 \mathrm{mmHg}$ systolic, $60-90 \mathrm{mmHg}$ diastolic; low: either systolic $<90 \mathrm{mmHg}$ or diastolic $<60 \mathrm{mmHg}$; high: either systolic $>140 \mathrm{mmHg}$ or diastolic $>90 \mathrm{mmHg}$; low/high: both high and low (one of each, systolic and diastolic); \#mean (s.D.). Bold indicates statistical significance.

https://ec.bioscientifica.com

https://doi.org/10.1530/EC-18-0418 (c) 2019 The authors Published by Bioscientifica Ltd

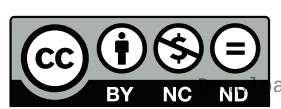

This work is licensed under a Creative Commons Attribution 4.0 International License. 
$\begin{array}{lll}\frac{5}{5} & \overline{0} & \frac{6}{0} \\ \frac{0}{0} & \frac{0}{0}\end{array}$

ำ 요 ำ

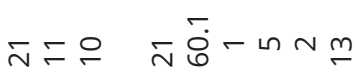

พ

분

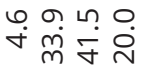

กับ

సं

$\stackrel{m}{\stackrel{\infty}{o}}$

$\stackrel{m}{m} \hat{m} \stackrel{m}{m} \stackrel{m}{m} \hat{\sigma}$

$\infty \stackrel{\text { กூ }}{\infty} \circ N$ L -

o $\stackrel{0}{\sim} \sim-N-$

$m \simeq 0-0$

$\bar{\sim}$

메에

in mi

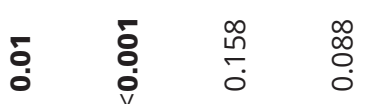

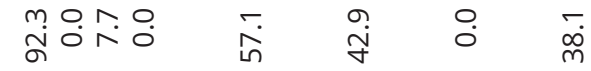

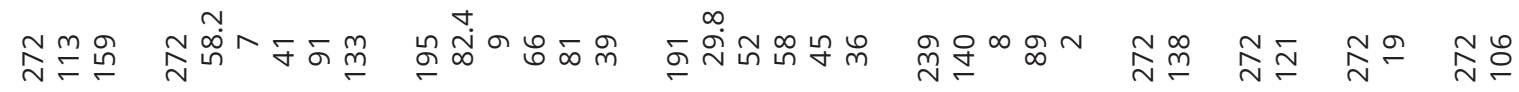

ถู่

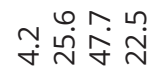

ạm $m$

$\stackrel{\circ}{m} \stackrel{\infty}{\sim} \stackrel{\infty}{\sim}$

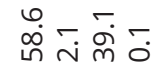

$\frac{-}{\overline{6}}$

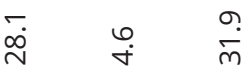

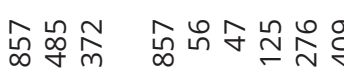

욤ำ

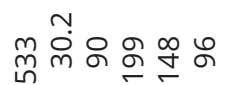

mํำ는 는

잉

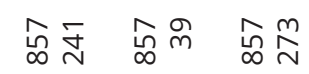

$\begin{array}{ll}0 & \text { ํํ } \\ 0 & 0 \\ 0 & 0\end{array}$

$\infty$
$\infty$
$\infty$
0

$\frac{0}{5}$

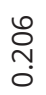

$\begin{array}{ll}\delta & \bar{o} \\ 0 & 0 \\ 0 & 0\end{array}$

ֻ̊ํ:

চ̊

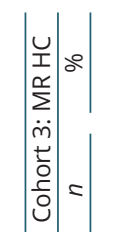

$\stackrel{m}{m}$

เ่i $\stackrel{\infty}{\sim} \stackrel{\infty}{\sim} \stackrel{\infty}{\infty}$

ㅇํㅇํำ ํํำ

ํํํ요ำ ํำ

†웡

$\stackrel{\infty}{N} \stackrel{\overbrace{}}{\curvearrowright}$

$\stackrel{\sim}{N} \quad: \quad \stackrel{\infty}{\sim}$

$\stackrel{\infty}{\sim} \stackrel{\infty}{\leftarrow} \stackrel{\infty}{\dot{n}}-\operatorname{n\llcorner }$

$\infty \stackrel{\circ}{\infty} \circ m+-$

$\infty \check{\dot{m}}$

$\dot{\rho} \sim N$ -

$\simeq$ n O No

$\stackrel{\infty}{\sim} \stackrel{\infty}{\leftarrow} \stackrel{\infty}{\sim} 0 \quad \stackrel{\infty}{\sim}$

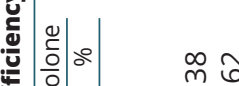

守芦芦

ํํำ

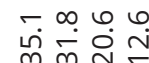

ஸึ

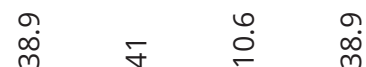

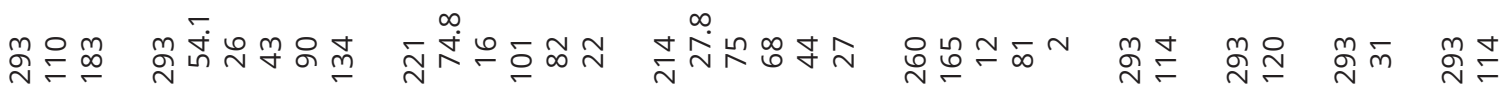

寸

$\sigma \stackrel{\infty}{m} \underset{\sim}{\wedge} \stackrel{\infty}{\infty} \infty$

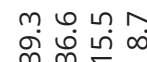

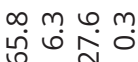

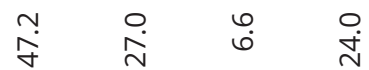

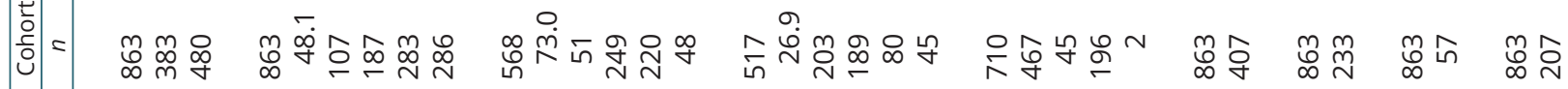
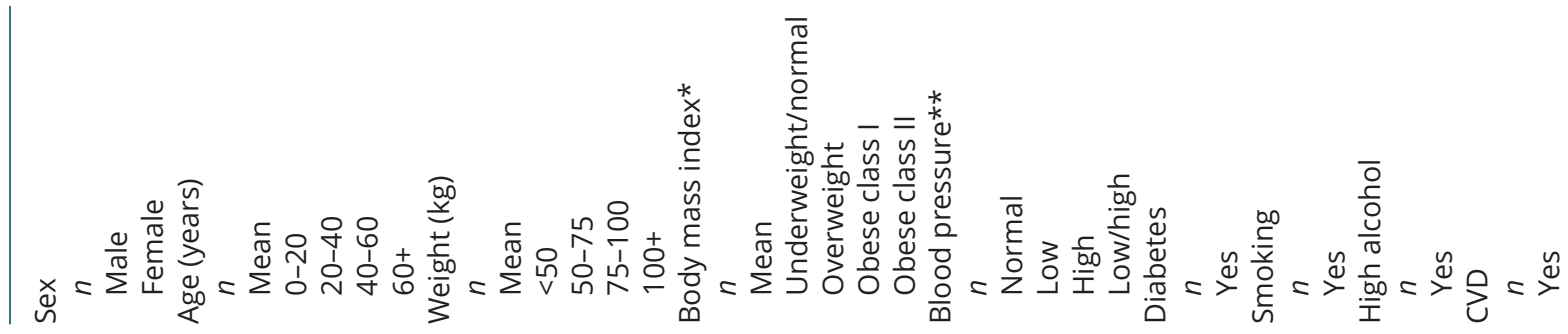


$$
\begin{aligned}
& \begin{array}{lll}
\frac{g}{S} & \overline{8} & \infty \\
\hline & 0 & 0 \\
0 & 0
\end{array}
\end{aligned}
$$

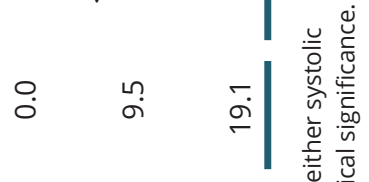

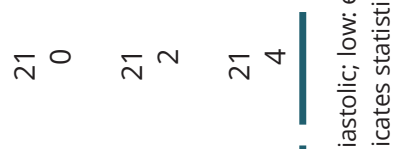

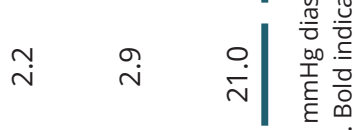

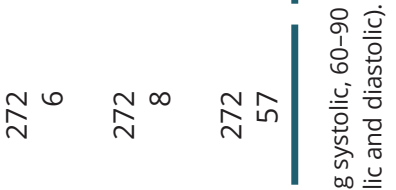

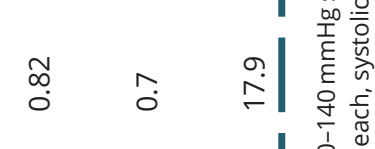

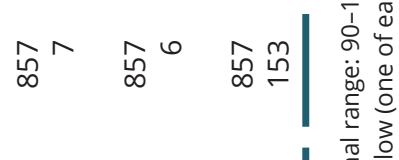

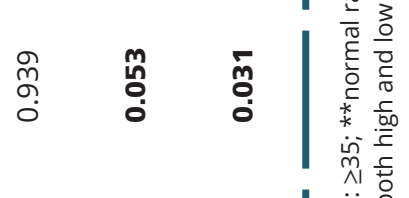

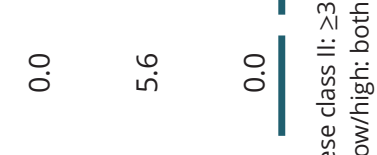

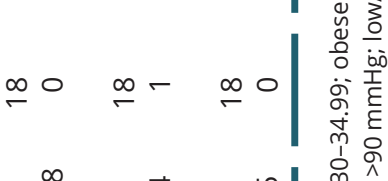

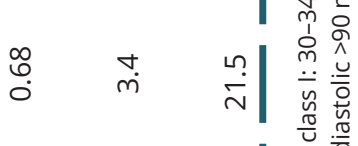

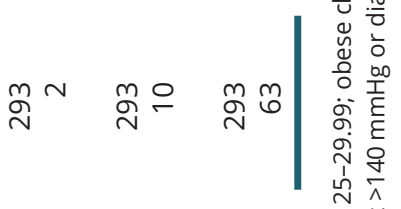

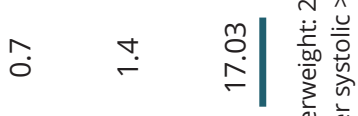

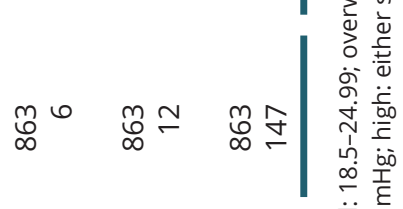

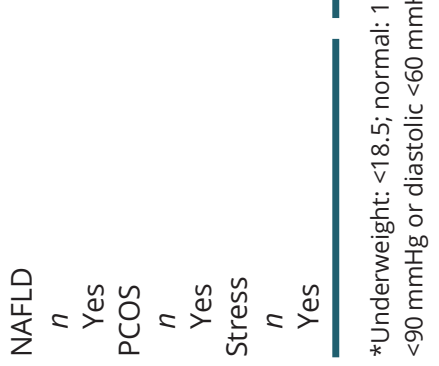

in the IR HC cohort were female, whereas this proportion was higher at $60 \%$ and $58 \%$ in the prednisolone and MR HC cohorts, respectively $(P<0.001)$. The presence of diabetes, smoking, CVD and PCOS varied significantly by treatment cohort (Table 1). The proportion of patients with diabetes was lowest in the prednisolone cohort (316/691, 45.7\%) and highest in the MR HC cohort (27/45, 60\%; $P=0.004)$. The proportion of patients with a history of smoking $(292 / 691,42.3 \% ; P<0.001)$ and CVD $(275 / 691$, $39.8 \% ; P<0.001)$ was highest in the prednisolone cohort. The proportion of patients with PCOS was highest in the MR HC cohort $(3 / 45,6.7 \% ; P=0.001)$. Although BMI did not vary significantly between treatment cohorts, there are some differences worth noting. Half the patients in the MR HC cohort were clinically obese; this was also true for one-third of patients in the other cohorts (Table 1). The Townsend score was similar across cohorts (Table 1).

Subgroup analyses showed that there were significant differences in age and the presence of diabetes, smoking, high alcohol consumption, CVD, PCOS and stress between the treatment cohorts in patients with primary AI (Table 2). The proportion of primary AI patients aged over 60 years was highest in the prednisolone cohort (134/293, 45.7\%; $P=0.005)$. The highest proportion of primary AI patients with a history of high alcohol consumption (31/293, 10.6\%; $P=0.04)$, CVD $(114 / 293,38.9 \% ; P<0.001)$, smoking $(120 / 293,40 \% ; P<0.001)$ and stress $(63 / 293,21.5 \%$; $P=0.03)$ was also seen in the prednisolone cohort. The highest proportion of primary AI patients with diabetes $(14 / 18,77.8 \% ; P=0.001)$ and PCOS $(1 / 18,5.6 \% ; P=0.05)$ was seen in the MR HC cohort (Table 2). In patients with secondary AI, there were significant differences in sex and history of diabetes, smoking and PCOS between the treatment cohorts (Table 2). The proportion of females was higher than males in the prednisolone cohort, whereas males predominated in the other cohorts $(P<0.001)$. The highest proportion of secondary AI patients with diabetes (524/857, 61.1\%; $P=0.01)$ was seen in the IR HC cohort. The highest proportion of secondary AI patients with a history of PCOS $(2 / 21,9.5 \% ; P<0.001)$ and smoking $(121 / 272,44.5 \% ; P<0.001)$ was seen in the MR HC and prednisolone cohorts, respectively. BMI did not vary significantly between treatment cohorts in either of these subgroups; however, it is worth noting that half the MR HC patients in both groups were obese.

\section{Outcomes}

The proportion of patients with one or more episodes of AC since the first prescription (within the study period)

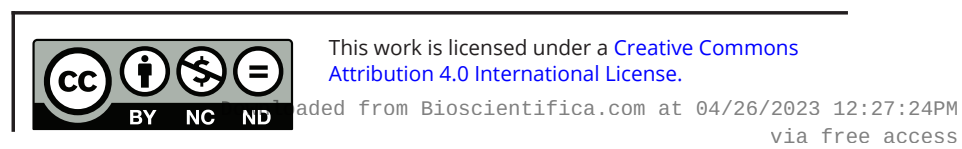


was $5.4 \%$ in the IR HC cohort (103/1912), 5.9\% in the prednisolone cohort (41/691) and $6.7 \%$ in the MR HC cohort (3/45). Considering the difference in patients' time in the study, the adjusted mean number of AC per patient per year after the first prescription was 0.02, 0.03 and 0.03 for the IR HC, prednisolone and MR HC cohorts, respectively (Table 3 ).

The primary and secondary resource use in patients with AI by patient cohort is displayed in Table 3. The mean number of face-to-face GP visits per patient per year ranged from 6.50 (s.D. 6.62) in the IR HC cohort to 9.54 (s.D. 7.87) in the prednisolone cohort, whereas the mean number of face-to-face nurse visits ranged from 1.59 (s.D. 2.66) in the MR HC cohort to 2.91 (s.D. 5.25) in the prednisolone cohort. The majority of secondary referrals were to orthopaedics $(7.8 \%, 150 / 1912)$ in the IR HC cohort, to general surgery $(11.6 \%, 80 / 691)$ in the prednisolone cohort and to ear nose and throat $(6.7 \%, 3 / 45)$ in the MR HC cohort. The mean number of $A \& E$ visits, inpatient hospital admissions and outpatient hospital admissions per patient per year ranged from 0.42 to 0.93 visits per patient per year. The estimated cost per patient per year (excluding drug costs) was $£ 2098$ for the IR HC cohort, £2609 for the prednisolone cohort and $£ 2237$ for the MR HC cohort (Table 3). The total cost remained similar for the IR HC and prednisolone cohorts but more than doubled for the MR HC when drug costs were included.

Table 3 Outcome and primary and secondary resource use in patients with adrenal insufficiency, by cohort.

\begin{tabular}{|c|c|c|c|c|c|c|}
\hline & $\begin{array}{c}\text { Cohort 1: } \\
\text { Immediate-release } \\
\text { hydrocortisone }(n=1912)\end{array}$ & $\operatorname{Cost}(£)^{*}$ & $\begin{array}{l}\text { Cohort 2: } \\
\text { Prednisolone }(n=691)\end{array}$ & Cost $(£)$ & $\begin{array}{c}\text { Cohort 3: } \\
\text { Modified-release } \\
\text { hydrocortisone }(n=45)\end{array}$ & Cost $(£)$ \\
\hline \multicolumn{7}{|l|}{ Outcome } \\
\hline \multicolumn{7}{|c|}{ Patients with one or more episodes of adrenal crisis } \\
\hline Mean (S.D.) & $0.02(0.15)$ & - & $0.03(0.18)$ & - & $0.03(0.13)$ & - \\
\hline \multicolumn{7}{|c|}{$\begin{array}{l}\text { Primary/secondary resource use/year } \\
\text { Face-to-face GP visit }\end{array}$} \\
\hline Mean (S.D.) & $6.50(6.62)$ & 240.87 & $9.54(7.87)$ & 352.98 & $9.11(8.98)$ & 337.07 \\
\hline \multicolumn{7}{|l|}{ Face-to-face nurse visit } \\
\hline Mean (s.D.) & $2.25(4.13)$ & 15.75 & $2.91(5.25)$ & 20.37 & $1.59(2.66)$ & 11.13 \\
\hline \multicolumn{7}{|l|}{ Home visit } \\
\hline Mean (s.D.) & $0.75(4.68)$ & 27.75 & $0.87(2.73)$ & 32.19 & $0.89(2.24)$ & 32.93 \\
\hline \multicolumn{7}{|l|}{ Phone call contact } \\
\hline Mean (S.D.) & $1.40(6.23)$ & 20.72 & $2.08(3.93)$ & 30.78 & $1.87(3.56)$ & 27.68 \\
\hline \multicolumn{7}{|l|}{$\begin{array}{l}\text { Outpatient hospital } \\
\text { admissions }\end{array}$} \\
\hline Mean (S.D.) & $0.62(1)$ & 92.98 & $0.93(0.95)$ & 139.46 & $0.85(1.22)$ & 127.47 \\
\hline \multicolumn{7}{|c|}{ For outpatient admissions - referrals per patient by specialty (\%) } \\
\hline Orthopaedic & $150(7.8)$ & - & $68(9.8)$ & - & $2(4.4)$ & - \\
\hline X-ray & $112(5.9)$ & - & $53(7.7)$ & - & $2(4.4)$ & - \\
\hline General surgery & $119(6.2)$ & - & $80(11.6)$ & - & $1(2.2)$ & - \\
\hline Ear, nose and throat & $105(5.5)$ & - & $65(9.4)$ & - & $3(6.7)$ & - \\
\hline Ophthalmology & $105(5.5)$ & - & $55(8.0)$ & - & $1(2.2)$ & - \\
\hline General medicine & $94(4.9)$ & - & $64(9.3)$ & - & 0 & - \\
\hline Endocrinology & $95(5.0)$ & - & $33(4.8)$ & - & 0 & - \\
\hline Dermatology & $71(3.7)$ & - & $42(6.1)$ & - & 0 & - \\
\hline Neurology & $64(3.3)$ & - & $23(3.3)$ & - & 0 & - \\
\hline Gynaecology & $58(3.0)$ & - & $32(4.6)$ & - & $1(2.2)$ & - \\
\hline Other & $568(29.7)$ & - & $333(48.2)$ & - & $9(20.0)$ & - \\
\hline \multicolumn{7}{|l|}{ A\&E visits } \\
\hline Mean (S.D.) & $0.42(1.2)$ & 65.94 & $0.59(1.1)$ & 92.63 & $0.64(0.87)$ & 100.48 \\
\hline \multicolumn{7}{|c|}{ Inpatient hospital admissions } \\
\hline Mean (S.D.) & $0.48(1.65)$ & 1633.91 & $0.57(0.99)$ & 1940.27 & $0.47(0.76)$ & 1599.87 \\
\hline Total estimated cost & & 2097.92 & & 2608.69 & & 2236.62 \\
\hline $\begin{array}{l}\text { Drug cost per patient per } \\
\text { year }\end{array}$ & & 1056.62 & & 13.04 & & 2922 \\
\hline $\begin{array}{l}\text { Total estimated cost } \\
\text { including drug cost }\end{array}$ & & 3154.54 & & 2621.73 & & 5158.62 \\
\hline
\end{tabular}

*Cost data derived from the Personal Social Services Research Unit and the National Schedule (Department of Health and Social Care).

https://ec.bioscientifica.com

https://doi.org/10.1530/EC-18-0418 (c) 2019 The authors Published by Bioscientifica Ltd

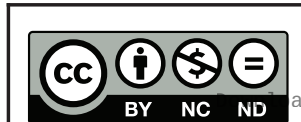

This work is licensed under a Creative Commons Attribution 4.0 International License. 


\section{Prescription details}

The corticosteroid prescription details for patients with AI are displayed in Table 4 . Over $80 \%$ of patients (2124/2648) were on IR HC $10 \mathrm{mg}$ tablets and $11.7 \%$ (310/2648) were on IR HC 20 mg tablets. About a quarter of patients received a prescription for prednisolone $5 \mathrm{mg}$ tablets (749/2648). Almost 90\% of patients (40/45) who received MR HC received $5 \mathrm{mg}$ tablets. For 22 patients on MR HC, robust patient-level and concomitant dosing data were available for interpretation. Of these, almost half $(45 \%, 10 / 22)$ were on monotherapy and the remaining patients $(55 \%, 12 / 22)$ received MR HC in combination with IR HC. The median total HC dose for these 22 patients was $20 \mathrm{mg}$ (IQR 15-23.8); the median MR HC dose was $10 \mathrm{mg}$ (IQR 5-18.8).

\section{Discussion}

This is to our knowledge the first real-world data description of the AI patient population in primary care, receiving different formulations of corticosteroid in the UK. This is a novel study of a large patient population with AI. We report which treatments are chosen, indications, risk factors, resource use and outcomes in the different treatment cohorts.

Almost three quarters of patients in our study were prescribed IR HC for AI. This is in line with HC being the most widely used glucocorticoid treatment in Europe for AI. In 946 patients enrolled in the European Adrenal Insufficiency Registry (EU-AIR), 91.8\% were treated with HC (17). A quarter of all patients in our study were on prednisolone. This is substantially higher than the $6.8 \%$ treated with prednisolone in the EU-AIR (17) and is perhaps

Table 4 Corticosteroid prescriptions for adrenal insufficiency patients.

\begin{tabular}{l} 
Top 4 IR HC and prednisolone prescriptions \\
\hline HC $10 \mathrm{mg}$ tablets \\
HC $20 \mathrm{mg}$ tablets \\
HC $5 \mathrm{mg} / 5 \mathrm{~mL}$ oral solution \\
HC $10 \mathrm{mg} / 5 \mathrm{~mL}$ oral suspension \\
Prednisolone $5 \mathrm{mg}$ tablets \\
Prednisolone $1 \mathrm{mg}$ tablets \\
Prednisolone $5 \mathrm{mg}$ gastro-resistant \\
tablets \\
Prednisolone $2.5 \mathrm{mg}$ gastro-resistant \\
tablets \\
MR HC since 2010 \\
HC 5 mg modified-release tablets \\
HC 20 mg modified-release tablets
\end{tabular}

Per patient $(\%)$ $2124 / 2648(80.2)$

$310 / 2648(11.7)$

$20 / 2648(0.8)$

$8 / 2648(0.3)$

$749 / 2648(28.3)$

$197 / 2648(7.4)$

293/2648 (11.1)

$153 / 2648(5.8)$

$40 / 45(88.9)$ $9 / 45(20.0)$ more than expected, but may reflect the continuing use of prednisolone for treatment of secondary AI arising from prednisolone treatment of other diseases, also referred to as tertiary AI. It has been suggested that prednisolone be used as first glucocorticoid replacement based on cost and absence of evidence for inferiority when compared to HC (10). Also, prednisolone may be more convenient for the patient than IR HC as it is prescribed once daily (as opposed to twice or thrice daily for IR HC) (18). This may be important in a patient group likely to also be taking other medications for comorbidities. Surprisingly, few patients $(<2 \%)$ in our study were prescribed MR HC for AI. MR HC was licensed in 2011 in the UK to treat adults with primary AI. The low usage may reflect a generally conservative approach by UK clinicians to adopt alternative medication formulations. Also, in an NHS aiming for cost-effectiveness, these drugs may be reserved only for certain patient groups where a clear additional benefit over other drugs or formulations has been demonstrated.

The largest category of patients in each cohort was aged over 60 years. This is in accordance with other published studies. A study on the clinical characteristics of patients with $\mathrm{AI}$ in a general hospital in Korea reported a mean age of 66.7 years (19), whilst nearly four-fifths of almost 25,000 patients hospitalised in Taiwan between 1996 and 2008 were aged at least 60 years at the time of their first AI diagnosis (20). Most studies have shown a female predominance in patients with $\mathrm{AI}(19,21)$; around $60 \%$ of patients in the prednisolone and MR HC cohorts in our study were female. This proportion was slightly lower at 50\% in the IR HC cohort; a similar finding was reported in the aforementioned Taiwanese study (20).

Our data seem to suggest that patients prescribed with prednisolone and MR HC have a higher prevalence of vascular risk factors than IR HC-treated patients. In our study, patients on prednisolone were older and had a greater history of smoking and CVD. Patients on MR HC had more PCOS and diabetes. There was also a larger proportion of patients in the MR HC group who were clinically obese compared to the other treatment cohorts, although this was not statistically significant probably due to the small sample size of this cohort. In a health system with finite resources, such as the UK NHS, medications like MR HC are used sparingly based on costeffectiveness and efficacy. Thus, in clinical practice in the $\mathrm{UK}, \mathrm{MR} \mathrm{HC}$ is likely to be prescribed to more high-risk patients. The higher prevalence of vascular risk factors seen in prednisolone-treated patients may also, as above, reflect the continuing use of prednisolone for treatment

This work is licensed under a Creative Commons Attribution 4.0 International License. 
of secondary AI arising from prednisolone treatment of other diseases, such as inflammatory arthropathies. The same pattern of risk factors was seen in primary AI, though for secondary AI, no treatment cohort stood out as higher risk.

Interestingly, there were similar numbers of patients with primary and secondary AI in our study although the literature reports a higher incidence of secondary AI (1). It should be noted however that $12 \%$ of patients in our study could not be allocated to the primary or secondary AI subgroup based on Read code alone. The proportion of patients on IR HC, prednisolone and MR HC was similar for primary and secondary AI and similar to the overall cohort. This suggests that clinicians are not selecting treatment options based on whether the patient has a diagnosis of primary or secondary AI. In addition, the similar Townsend score across treatment cohorts indicates that drugs are not being prescribed differently in areas of differing deprivation.

After the first prescription, the number of ACs per patient per year ranged from 0.02 to 0.03 across cohorts. This equates to 2-3/100 patients/year and is lower than the reported incidence of $\mathrm{AC}$ in patients with $\mathrm{AI}$ in Europe of 6-8/100 patients/year (22) likely reflecting underreporting. This could also be due to clinical coding systems, as it is likely that many ACs get coded as the infection that precipitated it rather than as an AC itself. It could also be that ACs are less frequently reported in secondary AI, which comprises close to half of the patient population in this study.

The resource use was quite similar for the various treatment cohorts, though it could be argued that it was slightly higher in the prednisolone group. This might reflect that these are higher risk patients with more comorbidities in general, thus requiring more visits to primary and secondary care. Further, it was surprising that endocrinology referrals did not feature more prominently in the dataset. The authors suggest the following potential explanations: (i) outpatient referrals may be more likely for complications of AI that require referral to specialities; (ii) the high number of orthopaedic referrals may be related to steroid induced osteoporosis and/or fractures in an elderly population; (iii) patients may have been under endocrinology care prior to the study period. It is likely that secondary care use is underestimated as the recording of these data in the THIN database relies on letters from or to secondary care. A study utilising a more granular secondary care dataset would be needed to understand the secondary care burden more fully. Based on these primary and secondary resource use statistics, we estimate an AI patient to cost the NHS between $£ 2600$ and $£ 5200$ per year. This is including drug costs, but excluding other factors that will have a financial impact such as reduced QoL. Thus, this is a significant resource utilisation for the NHS and suggests the need for better treatment and management of these patients.

The European Medicines Agency recommends a once daily MR HC dose of 20-30 mg (23). A lower dose may be sufficient in patients with some remaining endogenous cortisol (23). Surprisingly, almost $90 \%$ of patients in this study who received MR HC received $5 \mathrm{mg}$ tablets. Further analysis also showed that only around half were on monotherapy. It is difficult to interpret these prescribing data to infer dosing. One explanation may be that as MR $\mathrm{HC}$ is the only $5 \mathrm{mg}$ preparation of HC available, patients are being inappropriately prescribed it as part of a tailored regimen. For example, a regimen may comprise HC $10 \mathrm{mg}$ on waking, and a further $5 \mathrm{mg}$ at lunchtime and early evening may comprise an immediate-release $10 \mathrm{mg}$ tablet, and then the MR HC $5 \mathrm{mg}$ tablet for the further doses. The reporting is unlikely to be due to recording errors in THIN as prescriptions in primary care are generated electronically (i.e. the computerised entry made by the doctor is also used to issue the prescription to the patient) and have been shown to be accurate (14). Further education for prescribers on the appropriate dosing of MR HC may be warranted to ensure its appropriate use.

\section{Limitations}

Possible limitations of our study also need consideration. Firstly, the number of patients in the MR HC cohort is small (likely reflecting the highly selective use of MR $\mathrm{HC})$, making interpretation and definitive conclusions difficult. Secondly, the primary use of the Vision GP software (from which the THIN database is derived) is patient management, not medical research. As such, data will reflect only events that are deemed to be relevant to the patient's care and data quality depends entirely upon the accuracy and completeness of the data inputted by practice staff. Thus, the use of THIN data relies on the accuracy and completeness of clinical note recording and coding in primary care. This is an inherent limitation of any analysis of pre-existing data, which was not created for the purposes of research. Thirdly, THIN does not cover all UK GP practices, and pathways may be incomplete where patients have transferred from one GP practice to another. Fourthly, as discussed previously, data on secondary care visits and prescribing of medications in secondary care are incomplete and may have led to underestimation. 
In particular, secondary care visits may be variably recorded between practices by coding, scanning of hospital letters, or notes in a comments field, of which only the coded visits were available in this study. Fifthly, as patients were allocated to a cohort based on their first corticosteroid prescription, we are unable to account for use of multiple corticosteroid medications or switching corticosteroids. Finally, the assumptions required when analysing THIN data, including the use of search terms for the risk factor analysis, the interpretation applied to the MR concomitant dosing data, and the codes used to extract data on secondary care visits, will have introduced over or under estimations for certain variables. Future work should include examining primary care data that has been linked to Hospital Episode Statistics to more accurately define secondary care resource use.

\section{Conclusion}

We report data from a large population of patients in primary care in the UK reflecting a choice of glucocorticoid therapies. This study demonstrates that the majority of AI patients in the UK are being treated with IR HC. A higher proportion than expected are treated with prednisolone. Use of MR HC is infrequent, and where used, may be used incorrectly as part of a two/three-times daily regimen rather than once daily. The prednisolone and MR HC cohorts demonstrated a higher prevalence of vascular risk factors compared to IR HC, especially in those patients with primary AI. The occurrence of AC and primary and secondary resource use do not vary substantially between treatment cohorts, but they do indicate a significant resource utilisation to the NHS. Improved treatment and management of patients with $\mathrm{AI}$ is needed.

\section{Supplementary data}

This is linked to the online version of the paper at https://doi.org/10.1530/ EC-18-0418.

\section{Declaration of interest}

$R D M$ has received speaker fees and is on the steering committee of the European Adrenal Insufficiency Registry (EU-AIR) funded by Shire International $\mathrm{GmbH}$. K I and R P are employees of Shire. P V C has received honoraria for speaking at Shire-sponsored symposia. $\mathrm{K} \mathrm{H}$ is an employee of $\mathrm{pH}$ Associates.

\section{Funding}

This study was funded by Shire International $\mathrm{GmbH}$ and designed, implemented and reported by $\mathrm{pH}$ Associates in collaboration with Shire. Under the direction of the authors, medical writing support was provided by $\mathrm{Dr}$ Julia Granerod on behalf of $\mathrm{pH}$ Associates, with funding from Shire International $\mathrm{GmbH}$.

\section{References}

1 Arlt W \& Allolio B. Adrenal insufficiency. Lancet 2003361 1881-1893. (https://doi.org/10.1016/S0140-6736(03)13492-7)

2 Kong M-F \& Jeffcoate W. Eighty-six cases of Addison's disease. Clinical Endocrinology 199441 757-761. (https://doi. org/10.1111/j.1365-2265.1994.tb02790.x)

3 Chan S \& Debono M. Replication of cortisol circadian rhythm: new advances in HC replacement therapy. Therapeutic Advances in Endocrinology and Metabolism 20101 129-138. (https://doi. org/10.1177/2042018810380214)

4 NHS Choices. Symptoms: Addison's disease. Leeds, UK: NHS Digital, 2018. (available at: https://www.nhs.uk/conditions/addisons-disease/ symptoms/)

5 electronic Medicines Compendium (eMC). Plenadren $5 \mathrm{mg}$ and $20 \mathrm{mg}$ modified release tablets. Leatherhead, UK:

Datapharm. (available at: https://www.medicines.org.uk/emc/ medicine/28305)

6 Johannsson G, Bergthorsdottir R, Nilsson AG, Lennernas H, Hedner T \& Skrtic S. Improving glucocorticoid replacement therapy using a novel modified-release HC tablet: a pharmacokinetic study. European Journal of Endocrinology 2009161 119-130. (https://doi.org/10.1530/ EJE-09-0170)

7 Johannsson G, Nilsson AG, Bergthorsdottir R, Burman P, Dahlqvist P, Ekman B, Engström BE, Olsson T, Ragnarsson O, Ryberg M, et al. Improved cortisol exposure - time profile and outcome in patients with adrenal insufficiency: a prospective randomised trial of a novel hydrocortisone dual-release formulation. Journal of Clinical Endocrinology and Metabolism 201297 473-481. (https://doi. org/10.1210/jc.2011-1926)

8 Bergthorsdottir R, Nilsson AG, Gillberg P, Ekman B \& Wahlberg J. Health-related quality of life in patients with adrenal insufficiency receiving plenadren compared with immediate-release HC. Value in Health 201518 A616. (https://doi.org/10.1016/j. jval.2015.09.2145)

9 Isidori AM, Venneri MA, Graziadio C, Simeoli C, Fiore D, Hasenmajer V, Sbardella E, Gianfrilli D, Pozza C, Pasqualetti P, et al. Effect of once-daily, modified-release hydrocortisone versus standard glucocorticoid therapy on metabolism and innate immunity in patients with adrenal insufficiency (DREAM): a single-blind, randomised controlled trial. Lancet Diabetes and Endocrinology 20186 173-185. (https://doi.org/10.1016/S2213-8587(17)30398-4)

10 Amin A, Sam AH \& Meeran K. Glucocorticoid replacement. BMJ 2014 349 g4843. (https://doi.org/10.1136/bmj.g4843)

11 Joint Formulary Committee. British National Formulary (BNF) 64. London, UK: BMJ Group and Pharmaceutical Press, 2012.

12 UCL Institute of Epidemiology and Health Care. THIN database. London, UK: UCL, 2017. (available at: https://www.ucl.ac.uk/ iehc/research/primary-care-and-population-health/research/thindatabase)

13 Blak BT, Thompson M, Dattani H \& Bourke A. Generalisability of The Health Improvement Network (THIN) database: demographics, chronic disease prevalence and mortality rates. Informatics in Primary Care 201119 251-255. (https://doi.org/10.14236/jhi.v19i4.820)

14 Lewis JD, Schinnar R, Bilker WB, Wang X \& Strom BL. Validation studies of The Health Improvement Network (THIN) database for pharmacoepidemiology research. Pharmacoepidemiology and Drug Safety 200716 393-401. (https://doi.org/10.1002/pds.1335)

15 Curtis LA \& Burns A. Unit costs of health and social care. Canterbury, UK: Personal Social Services Research Unit, University of Kent, 2017. (https://doi.org/10.22024/ UniKent/01.02/65559)

16 Department of Health and Social Care. NHS reference costs 2015 to 2016. London, UK: Department of Health and Social Care, 2016 (available at: https://www.gov.uk/government/publications/nhsreference-costs-2015-to-2016) 
17 Murray RD, Ekman B, Jones BA, Marelli C, Quinkler M \& Zelissen P. Clinical management of adrenal insufficiency shows significant heterogeneity: data from the EU-AIR study. Endocrine Abstracts 201537 EP39. (https://doi.org/10.1530/endoabs.37.EP39)

18 Smith DJF, Prabhudev H, Choudhury S \& Meeran K. Prednisolone has the same cardiovascular risk profile as hydrocortisone in glucocorticoid replacement. Endocrine Connections 20176 766-772. (https://doi.org/10.1530/EC-17-0257)

19 Lee YY, Cho NH, Lee JW, Kim NK, Kim HS \& Kim MK. Clinical characteristics of patients with adrenal insufficiency in a general hospital. Endocrinology and Metabolism 201732 83-89. (https://doi. org/10.3803/EnM.2017.32.1.83)

20 Chen YC, Lin YH, Chen SH, Chen YC, Chou LF, Chen TJ \& Hwang SJ. Epidemiology of adrenal insufficiency: a nationwide study of hospitalisations in Taiwan from 1996 to 2008.
Journal of the Chinese Medical Association 201376 140-145. (https:// doi.org/10.1016/j.jcma.2012.11.001)

21 Ekman B, Fitts D, Marelli C, Murray RD, Quinkler M \& Zelissen PM. European Adrenal Insufficiency Registry (EU-AIR): a comparative observational study of glucocorticoid replacement therapy. BMC Endocrine Disorders 201414 40. (https://doi.org/10.1186/1472-682314-40)

22 Chabre O, Goichot B, Zenaty D \& Bertherat J. Group 1. Epidemiology of primary and secondary adrenal insufficiency: prevalence and incidence, acute adrenal insufficiency, long-term morbidity and mortality. Annales d'Endocrinologie 201778 490-494. (https://doi. org/10.1016/j.ando.2017.10.010)

23 European Medicines Agency. Plenadren; hydrocortisone. Brussels, Belgium: European Medicines Agency, 2017. (available at: https:// www.ema.europa.eu/en/medicines/human/EPAR/plenadren)

Received in final form 6 December 2018

Accepted 18 December 2018

Accepted Preprint published online 18 December 2018
This work is licensed under a Creative Commons Attribution 4.0 International License.

ded from Bioscientifica.com at 04/26/2023 12:27:24PM 